\title{
Copolymerization Behavior of $\beta$-Angelica Lactone and Styrene in the Presence of Organoaluminum Chlorides
}

\author{
Tadamichi HiRABAYASHI and Kenji YoKOTA \\ Materials Research Laboratory, Nagoya Institute of Technology, \\ Gokiso-cho, Showa-ku, Nagoya 466, Japan
}

(Received March 17, 1982)

\begin{abstract}
In order to synthesize polymers containing lactone units in the backbone chains and use them as membranes, copolymerization of $\beta$-angelica lactone ( $\beta$-AL) with styrene was carried out. Using $\alpha, \alpha^{\prime}$-azobisisobutyronitrile at $60^{\circ} \mathrm{C}, \beta$-AL did not copolymerize readily. In the presence of ethylaluminum sesquichloride or diethylaluminum chloride as a complexing reagent in toluene at $20^{\circ} \mathrm{C}$, however, $\beta$-AL copolymerized much more readily. Spontaneous initiation took place and a copolymer containing about $50 \mathrm{~mol} \%$ of $\beta$-AL units was obtained under the most favorable conditions. Nevertheless, it seemed unlikely that regular, highly alternating sequences could be achieved in this manner, in contrast to the well-known Lewis acid-complexed copolymerization of acrylic esters and styrene. NMR studies demonstrated that, while the binary complex between $\beta$-AL and ethylaluminum sesquichloride was formed almost instantly and completely, the ternary complex between styrene, $\beta$-AL and ethylaluminum sesquichloride had a rather low stability constant $\left(\leqslant 0.05 \mathrm{dm}^{3} \mathrm{~mol}^{-1}\right.$ ) which accounts for the imperfectly alternating sequences.

KEY WORDS $\beta$-Angelica Lactone (5-Methyl-2 $H, 5 H$-furanone-2) / Styrene /

Organoaluminum Chloride / Alternating Copolymer / Hanna-Ashbough

Plot / Stability Constant of Ternary Complex /
\end{abstract}

Academic investigation of models of biological membranes and industrial demand have generated considerable interest in the molecular design of polymeric membranes. For example, certain polymeric membranes containing lactone structures in their side chains have been reported to effect the active transport of alkali metal ions. ${ }^{1-3}$

If $\alpha, \beta$-unsaturated lactone monomers are polymerized by a radical process, the resulting polymers will probably have lactone structures in their backbone chains and function as useful membranes. For practical purposes, such a route is not likely to be fruitful since the monomers do not polymerize or copolymerize readily under conventional radical polymerization conditions. ${ }^{4}$ As an alternative synthesis, intramolecular reactions between neighbor- ing functional groups suitable for esterification on polymer chains have been carried out. We have already demonstrated successful cases in which specially-designed alternating copolymers have been employed for this purpose. ${ }^{5,6}$

However, $\gamma$-crotonolactone and styrene ${ }^{7}$ were reported to give an alternating copolymer in the presence of stannic chloride. This implies the possibility of using $\alpha, \beta$-unsaturated lactone monomers. In this paper, the authors report the copolymerization of $\beta$-angelica lactone (5-methyl- $2 \mathrm{H}, 5 \mathrm{H}$ furanone-2) and styrene with organoaluminum chlorides. The reaction takes place spontaneously and readily according to the following equation, but does not give a perfect alternating copolymer. The reason for this is discussed.

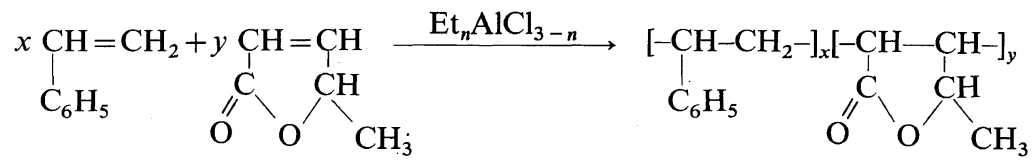




\section{EXPERIMENTAL}

\section{Monomers and Other Reagents}

$\beta$-Angelica lactone ( $\beta$-AL) was prepared through the triethylamine-catalyzed rearrangement of $\alpha$ angelica lactone synthesized from levulinic acid in the presence of polyphosphoric acid. This compound was dried on calcium hydride and freshly redistilled under nitrogen, bp $56.5-57^{\circ} \mathrm{C} \quad(2.6$ $\mathrm{mmHg}$ ); NMR (neat), $\delta 1.19$ (d, 3H, $J=8.0 \mathrm{~Hz}$ ), $3.85(\mathrm{q}-\mathrm{t}, 1 \mathrm{H}, J=8.0$ and $2.1 \mathrm{~Hz}), 5.90$ (d-d, $1 \mathrm{H}, J=$ 5.9 and $2.1 \mathrm{~Hz},>\mathrm{CH}-\mathrm{CH}=\mathrm{CH}-), 7.31 \mathrm{ppm}(\mathrm{d}-\mathrm{d}$, $1 \mathrm{H}, J=5.9$ and $2.1 \mathrm{~Hz},-\mathrm{CH}=\mathrm{CH}-\mathrm{CO}-) ; n^{26}$ 1.4641 .

Commercially available styrene (St) was purified as usual, dried on porous barium oxide, and freshly distilled under nitrogen.

Diethylaluminum chloride $\left(\mathrm{Et}_{2} \mathrm{AlCl}\right)$ and ethylaluminum sesquichloride $\left(\mathrm{Et}_{3} \mathrm{Al}_{2} \mathrm{Cl}_{3}\right)$ were obtained from Ethyl Co., redistilled under reduced pressure of argon, and used as about $4 \mathrm{~mol} \mathrm{dm}^{-3}$ toluene solutions.

Toluene was washed with concd sulfuric acid and water, dried on sodium wire, and then distilled.

\section{Copolymerization}

All feeding procedures were carried out under an argon atmosphere. In a dry ampoule, $\beta$-AL and a calculated volume of toluene solution of $\mathrm{Et}_{2} \mathrm{AlCl}$ or $\mathrm{Et}_{3} \mathrm{Al}_{2} \mathrm{Cl}_{3}$ were placed at $-78^{\circ} \mathrm{C}$ and allowed to warm to $0^{\circ} \mathrm{C}$ in $30 \mathrm{~min}$. After cooling again to $-78^{\circ} \mathrm{C}$, St was added to the mixture. The ampoule was sealed off and immersed in a thermostated bath at $20^{\circ} \mathrm{C}$ for a prescribed time interval. The content of the ampoule was poured into a large excess of cold methanol containing $3 \mathrm{vol} \%$ of concd hydrochloric acid. The resulting copolymer was collected by centrifugation reprecipitated twice from a dimethyl sulfoxide (DMSO) solution into methanol, and dried in vacuo at $60^{\circ} \mathrm{C}$. It was possible to replace DMSO by chloroform in the case of copolymers with higher St content.

With $\alpha, \alpha^{\prime}$-azobisisobutyronitrile (AIBN), radical copolymerization was carried out at $60^{\circ} \mathrm{C}$, followed by the same work-up procedures above.

\section{Analyses}

${ }^{1} \mathrm{H}$ NMR spectra and IR spectra were taken on a Hitachi R-20B or R-24A spectrometer and on a JASCO IR-DG-701G spectrometer, respectively.
Elemental analysis was carried out on a Yanagimoto CHN-MT-1S. GPC in tetrahydrofuran was recorded by both UV at $254 \mathrm{~nm}$ and differential refractometrical (RI) monitors on a Toyo Soda HLG-802 UR model equipped with TSK-G5000 $\mathrm{H}_{8}$ and $-\mathrm{G} 2500 \mathrm{H}_{10}$ columns.

\section{RESULTS AND DISCUSSION}

\section{Copolymerization of $\beta-A L$ and St with Organo- aluminum Chlorides}

Table II summarizes the results of copolymerization of $\beta$-AL and $\mathrm{St}$ in the presence of organoaluminum chlorides in toluene at $20^{\circ} \mathrm{C}$, and also includes the results of the radical polymerization at $60^{\circ} \mathrm{C}$ for comparison.

Temperatures within a range of $-78-0^{\circ} \mathrm{C}$ were usually employed in the well-known alternating copolymerization where popular acrylic monomers and electron-donating monomers were examined with organoaluminum catalysts. ${ }^{8}$ However, preliminary experiments with the present reactants at $0^{\circ} \mathrm{C}$ required much longer periods of time to attain detectable conversion $(\sim 1 \mathrm{wt} \%)$ and were failure from a practical standpoint of view.

Organoaluminum chlorides in larger quantities or with stronger Lewis-acidity resulted in a faster copolymerization.

Figure 1 shows GPC charts of the copolymers No. 21-28. Each chart exhibits the same type of dispersion pattern with one peak in both the UVand RI-monitoring. This suggests that competitive propagating paths as in the case of a cationic process which produces polystyrene or cycloaddition giving oligomers of $\beta$-AL were practically negligible. Compared with the reference scale based on standard polystyrene samples, the mean molecular weight $\left(M_{w}\right)$ of these copolymers lay roughly in the range $1.0-6.0 \times 10^{4}$ and increased gradually with increasing St content.

The structure of the copolymers was investigated by IR and NMR spectroscopy. An absorption due to the five-membered lactone unit appeared at 1765 $\mathrm{cm}^{-1}$ in the IR spectrum for each copolymer obtained with an organoaluminum chloride. However, no clear absorption by carboxyl groups near 1715 $\mathrm{cm}^{-1}$ was observed. A typical spectrum is displayed in Figure 2. The IR spectra of the polymers originating from the AIBN system were essentially identical to that of polystyrene. 


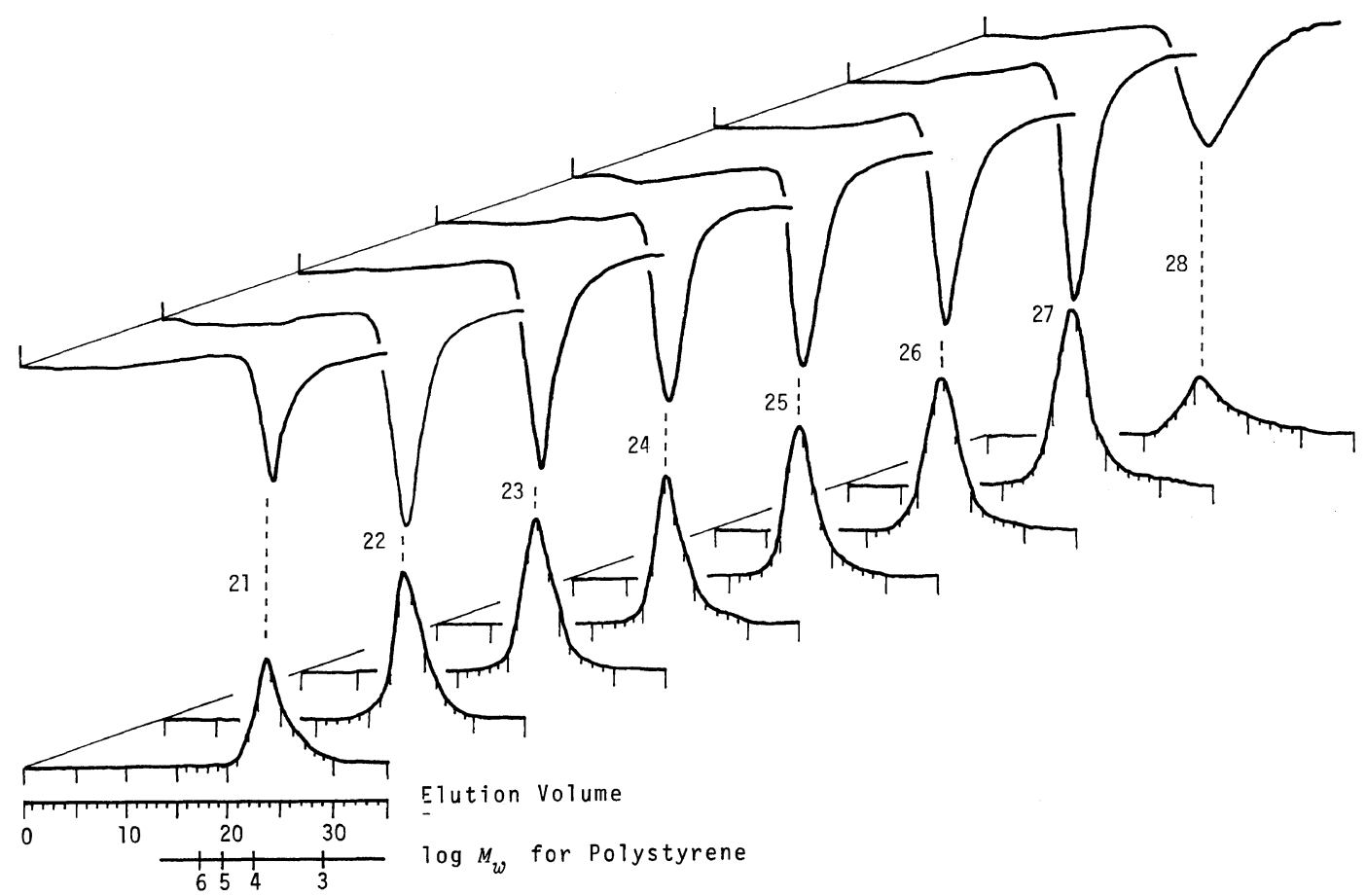

Figure 1. Gel-permeation chromatographs of $\beta$-AL-St copolymers, No. $21-28$, monitored by UV (lower) and RI (upper curve).

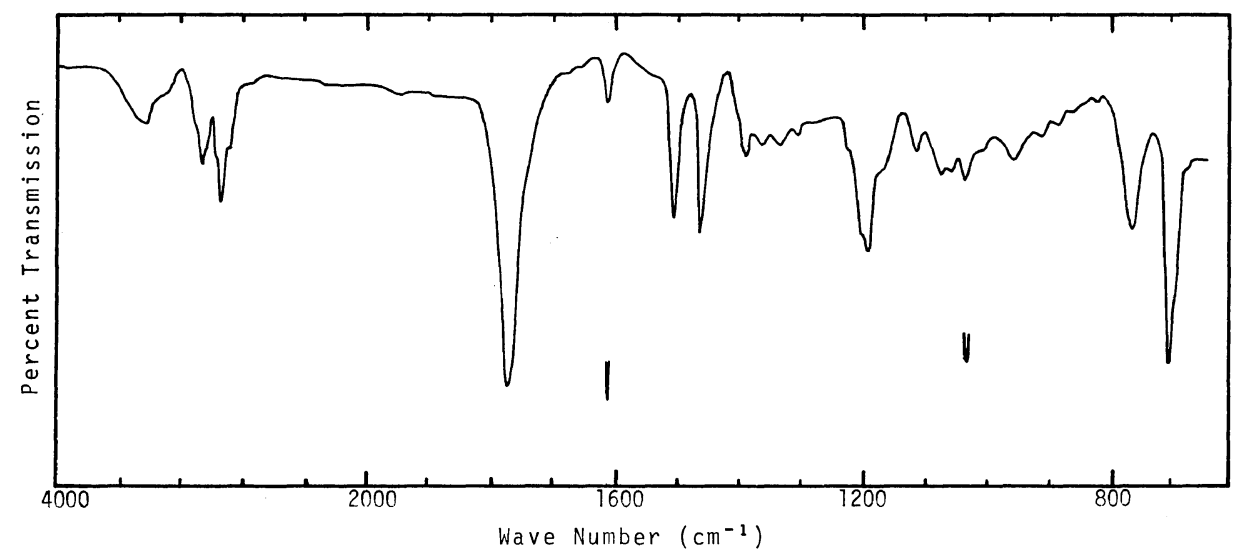

Figure 2. IR spectrum of $\beta$-AL-St copolymer (No. 23) on $\mathrm{KBr}$-disk.

The NMR spectra of these copolymers in DMSO- $d_{6}$ (or sometimes in deuterochloroform) at $35^{\circ} \mathrm{C}$ showed three distinguishable absorptions at 7.6-6.0, 4.6-3.4, and above $3.4 \mathrm{ppm}$ from hexamethyldisiloxane (HMDS), as illustrated in Figure 3. These may be assigned to $\mathrm{C}_{6} \mathrm{H}_{5}-,>\mathrm{CH}-\mathrm{OCH}-$, and other protons of $\mathrm{St}$ and $\beta$-AL units, respec- tively. This assignment is not at variance with the peak intensity ratios. There was hardly any evidence found to support ring-opening of the lactone ring, as was predictable from the literature. ${ }^{9}$ Thus, the structure of these copolymers must have the following formulas. 


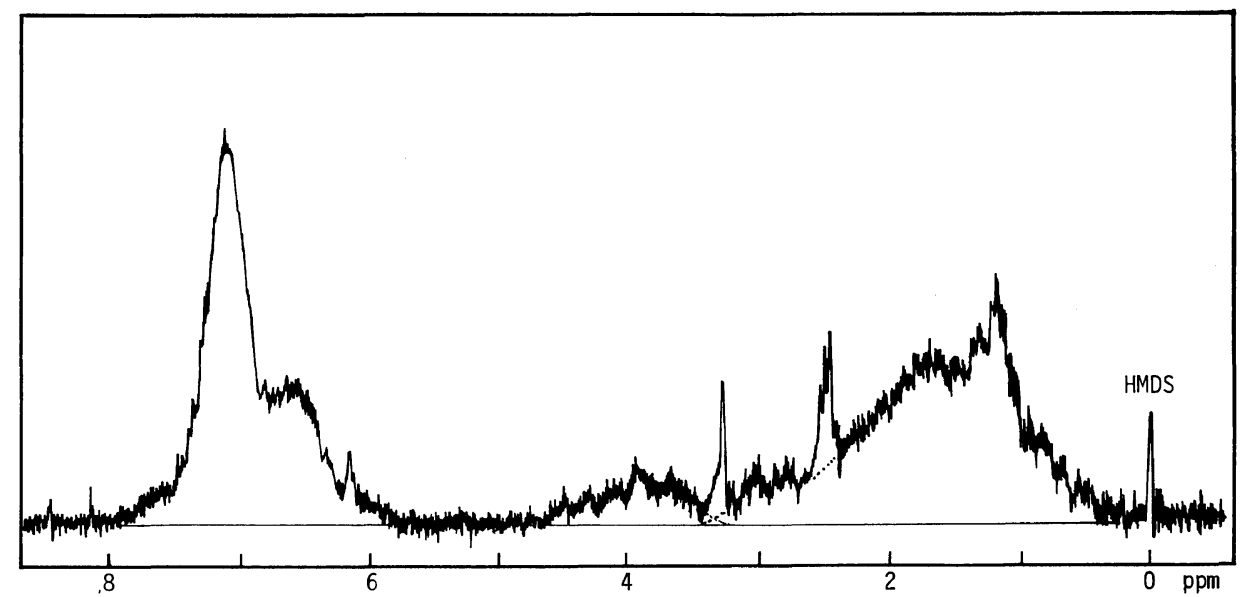

Figure 3. $60 \mathrm{MHz}{ }^{1} \mathrm{H}-\mathrm{NMR}$ spectrum of $\beta$-AL-St copolymer (No. 24$)$ in DMSO- $d_{6}$ at $35^{\circ} \mathrm{C}$. (2.5 ppm: undeutero-DMSO, 3. 3 ppm: see text).<smiles>CC1OC(=O)C(CCC(I)c2ccccc2)C1C</smiles>

The mole fraction ( $x$ or $y$ ) of each unit was determined by NMR and also by the elemental analysis shown in Table I. Though there is no serious discrepancy in these analyses, small amounts of water (detected at $c a$. $3.3 \mathrm{ppm}$ in NMR) should be taken into account in determining how $\mathrm{C}, \mathrm{H}$, and $\mathrm{O}$ are related to each other in the latter. This treatment showed better agreement in the analyses.

Figure 4 shows a diagram of monomer feed $v s$. copolymer composition under various copolymerization conditions. It can be seen that while $\beta$ $\mathrm{AL}$ was hardly incorporated into the resulting polymers with AIBN, the fraction of $\beta$-AL units was impressively enhanced in the organoaluminumcatalyzed system. The broken line in Figure 4 represents the theoretical curve based on a pair of reactivity ratios, $r_{1}=0.036\left(\mathrm{M}_{1}, \beta-\mathrm{AL}\right)$ and $r_{2}=0.67$ $\left(\mathrm{M}_{2}, \mathrm{St}\right)$. This curve is in agreement with the experimental results $(O)$ obtained with the ratio $\mathrm{Et}_{3} \mathrm{Al}_{2} \mathrm{Cl}_{3} / \beta-\mathrm{AL}=0.5$, suggesting that propagation proceeded according to the Mayo-Lewis' scheme. In other words, $\beta$-AL, with a half the molar amount of $\mathrm{Et}_{3} \mathrm{Al}_{2} \mathrm{Cl}_{3}$, can apparently be characterized in terms of $Q \simeq 0.36$ and $e \simeq 1.13$. $\beta$-AL is now regarded as suitable monomer for the synthesis of a lactonecontaining polymer through an organoaluminum chloride and can no longer be disregarded as a monomer having no function.

However, a perfectly alternating copolymer could not be obtained even when the amount of an organoaluminum catalyst was the same as that of $\beta$ AL. This system thus differs from many others ${ }^{8,10,11}$ recognized as the Lewis acid-complexed alternating copolymerizations. The explanation for this is discussed below.

\section{Formation of Binary Complex of $\beta-A L$ with $\mathrm{Et}_{3} \mathrm{Al}_{2} \mathrm{Cl}_{3}$}

Complexation between $\beta$-AL and $\mathrm{Et}_{3} \mathrm{Al}_{2} \mathrm{Cl}_{3}$ was investigated by recording the NMR spectra of their mixtures at $20^{\circ} \mathrm{C}$. In keeping the total mole numbers constant $\left(5.05 \times 10^{-3}\right)$, the mole ratios were varied. So as to avoid interference from other interactions, no additional solvent was added except one drop of toluene as an internal reference.

Each resonance due to $\beta$-AL protons in the mixture was observed in a magnetic field lower than the corresponding resonance of pure $\beta$-AL. The dependence of the chemical shift difference $\left(\delta_{\text {obsd }}{ }^{-}\right.$ $\delta_{\text {pure }}$ ) on the fraction of $\mathrm{Et}_{3} \mathrm{Al}_{2} \mathrm{Cl}_{3}$ in the mixture is illustrated in Figure 5. More than equimolar amounts of $\mathrm{Et}_{3} \mathrm{Al}_{2} \mathrm{Cl}_{3}$ added to $\beta$-AL resulted in almost the same value of $\delta_{\text {obsd }}-\delta_{\text {pure }}$ for the each proton of $\beta$-AL. On standing for a while as the temperature was lowered to $15^{\circ} \mathrm{C}$, two kinds of peaks for each proton of $\beta$-AL were observed in the sample whose initial $\left[\mathrm{Et}_{3} \mathrm{Al}_{2} \mathrm{Cl}_{3}\right] /[\beta$-AL] ratio was adjusted to 0.25 . Each intensity ratio of 
Table I. Copolymerization of $\beta$-angelica lactone $\left(\beta\right.$-AL) and styrene (St) in toluene at $20^{\circ} \mathrm{C}$

\begin{tabular}{|c|c|c|c|c|c|c|c|c|}
\hline \multirow{2}{*}{$\begin{array}{c}\text { Exptl. } \\
\text { No. }\end{array}$} & \multicolumn{2}{|c|}{ Monomer feed $/ \mathrm{mmol}^{\mathrm{a}}$} & \multirow{2}{*}{$\frac{[a l]^{\mathrm{b}}}{[\beta-\mathrm{AL}]}$} & \multirow{2}{*}{$\frac{\text { Time }}{\mathrm{h}}$} & \multirow{2}{*}{$\frac{\text { Conversion }}{w \mathrm{w} \%}$} & \multicolumn{2}{|c|}{ Anal. Found } & \multirow{2}{*}{$\begin{array}{c}\begin{array}{c}\beta \text {-AL unit of } \\
\text { copolymer }^{\mathrm{c}}\end{array} \\
\mathrm{mol} \%\end{array}$} \\
\hline & $\beta$-AL & St & & & & $\mathrm{C} / \%$ & $\mathrm{H} / \%$ & \\
\hline 11 & 26.4 & 9.5 & 0.3 & $11^{\mathrm{d}}$ & 1.1 & 80.79 & 7.10 & $35.7(38.3)$ \\
\hline 12 & 22.0 & 13.9 & $\prime \prime$ & $" \prime$ & 1.5 & & & 30.4 \\
\hline 13 & 16.5 & 19.1 & $" \prime$ & $\prime \prime$ & 1.9 & 84.46 & 7.47 & $26.7(25.5)$ \\
\hline 14 & 12.1 & 23.4 & $" 1$ & $" 1$ & 1.6 & & & 18.5 \\
\hline 15 & 7.7 & 27.7 & " & "' & 1.9 & & & 10.2 \\
\hline 21 & 33.8 & 2.3 & 0.5 & 28 & 2.4 & 74.47 & 6.95 & $57.5(57.8)$ \\
\hline 22 & 30.3 & 5.7 & ", & " & 2.3 & 76.87 & 7.06 & $51.4(51.0)$ \\
\hline 23 & 26.4 & 9.5 & $" \prime$ & 23 & 2.7 & 77.61 & 6.97 & $48.4(48.6)$ \\
\hline 24 & 22.0 & 13.9 & $" \prime$ & $\prime \prime$ & 2.8 & 78.31 & 7.04 & $44.7(46.3)$ \\
\hline 25 & 16.5 & 19.1 & $" \prime$ & $" \prime$ & 3.0 & 80.95 & 7.27 & $35.7(37.8)$ \\
\hline 26 & 12.1 & 23.4 & $" 1$ & 22 & 2.7 & 81.96 & 7.24 & $31.8(34.5)$ \\
\hline 27 & 7.7 & 27.7 & " & 20 & 2.6 & 84.50 & 7.31 & $23.8(26.1)$ \\
\hline 28 & 4.4 & 31.1 & $" \prime$ & 28 & 6.0 & 88.27 & 7.56 & $12.1(13.5)$ \\
\hline 31 & 26.4 & 9.5 & 1.0 & 30 & 4.0 & & & 48.0 \\
\hline 32 & 22.0 & 13.9 & $" 1$ & 20 & 2.2 & & & 45.5 \\
\hline 33 & 16.5 & 19.1 & " & " & 1.7 & & & 40.7 \\
\hline $\mathrm{R}-1^{\mathrm{e}}$ & 26.4 & 9.5 & - & 14 & 2.0 & 89.62 & 7.63 & $8.1(9.0)$ \\
\hline $2^{\mathrm{e}}$ & 16.5 & 19.1 & ", & 3 & $5.9^{f}$ & 92.19 & 7.76 & $-(0.3)$ \\
\hline $3^{e}$ & 7.7 & 27.7 & "' & 3 & $6.0^{f}$ & & & - \\
\hline
\end{tabular}

a $[\beta-\mathrm{AL}+\mathrm{St}]_{\mathrm{av}} 3.0 \mathrm{~mol} \mathrm{dm}{ }^{-3}$.

b $a l=\mathrm{Et}_{2} \mathrm{AlCl}$ for samples No.11-15 and 31-33: $a l=\mathrm{Et}_{3} \mathrm{Al}_{2} \mathrm{Cl}_{3}$ for No. $21-28$.

c Estimated by NMR. Values in parentheses are based on carbon content.

d After treatment for $30 \mathrm{~h}$ at $0^{\circ} \mathrm{C}$. From the duplicated ampoules of No. $11-15$ examined for $30-48 \mathrm{~h}$ at $0^{\circ} \mathrm{C}$, any detectable amount of copolymer could not be obtained.

e With AIBN (15 mg, $0.5 \mathrm{~mol} \%$ for monomers) at $60^{\circ} \mathrm{C}$.

${ }^{f}$ Calculated on St basis as polystyrene.

these paired peaks was approximately $1: 3$ and the chemical shifts of the smaller peaks were very close to those of the equimolar mixture at $20^{\circ} \mathrm{C}$, as can be seen from Figure 6 . Each of these peak pairs fused to form one broad peak above $20^{\circ} \mathrm{C}$. This suggests that the equimolar complex formation in the binary system is nearly completed under the given conditions for copolymerization. It should be noted that in the sample whose initial component ratio was adjusted to 1.0, such a peak separation did not occur under the measurement conditions but a maximum value of $\delta_{\text {obsd }}-\delta_{\text {pure }}$ for each proton was comparable to that of the $1: 1$ complex.

\section{Ternary Complex in St- $\beta-A L-E t_{3} \mathrm{Al}_{2} \mathrm{Cl}_{3}$ System}

In successful alternating copolymerizations with various Lewis acids, it has been repeatedly shown that ternary complexes like "Donor monomer... Acrylic monomer/Lewis acid" play important roles in the regulation of the alternating sequences. However, the copolymers obtained in the present work were not perfectly alternating and it is necessary to study the ternary complex under the copolymerization conditions.

Based on the discussion in the preceding section, it may be assumed that the mixture of $\beta$-AL $(0.08$ $\left.\mathrm{cm}^{3}\right)$ and $\mathrm{Et}_{3} \mathrm{Al}_{2} \mathrm{Cl}_{3}\left(0.10 \mathrm{~cm}^{3}\right)$ involved at least $8.3 \times 10^{-4} \mathrm{~mol}$ of the binary complex abbreviated as $\beta$-AL/al. With excess amounts of St, NMR measurement was performed at $20^{\circ} \mathrm{C}$ in cyclohexane- $d_{12}$ to control the concentration with an extremely small quantity of toluene as a reference. The results are summarized in Table II. 


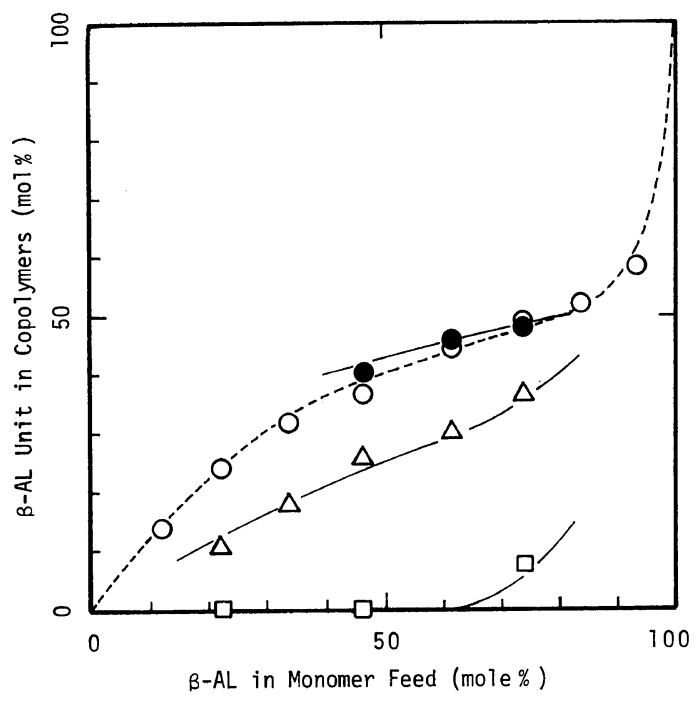

Figure 4. Diagram of monomer feed vs. copolymer composition for copolymerization between $\beta$-AL and $\mathrm{St}$ under various catalytic conditions: $O,\left[\mathrm{Et}_{2} \mathrm{AlCl}\right] /[\beta$ $\mathrm{AL}]=1.0,20^{\circ} \mathrm{C} ; \mathrm{O},\left[\mathrm{Et}_{3} \mathrm{Al}_{2} \mathrm{Cl}_{3}\right] /[\beta-\mathrm{AL}]=0.5,20^{\circ} \mathrm{C} ; \triangle$, $\left[\mathrm{Et}_{2} \mathrm{AlCl}\right] /[\beta-\mathrm{AL}]=0.3,20^{\circ} \mathrm{C} ; \square, \mathrm{AIBN} 0.5 \mathrm{~mol} \%, 60^{\circ} \mathrm{C}$. See text as to the broken line.

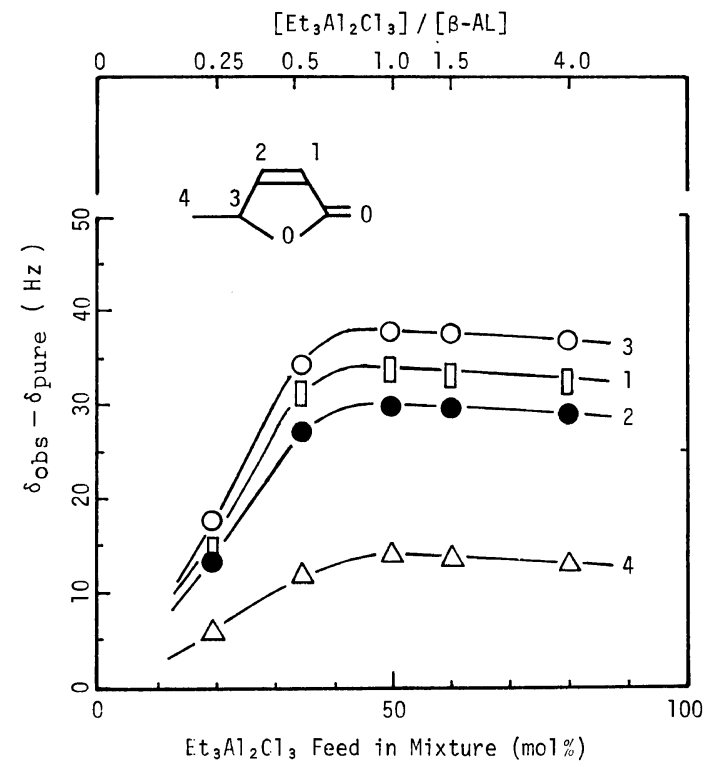

Figure 5. Dependence of the chemical shift difference $\left(\delta_{\text {obsd }}-\delta_{\text {pure }}\right)$ on the fraction of $\mathrm{Et}_{3} \mathrm{Al}_{2} \mathrm{Cl}_{3}$ in the binary mixtures of $\mathrm{Et}_{3} \mathrm{Al}_{2} \mathrm{Cl}_{3}$ and $\beta$-AL. The numbers on the curves correspond to the resonance of numbered protons of $\beta$-AL.

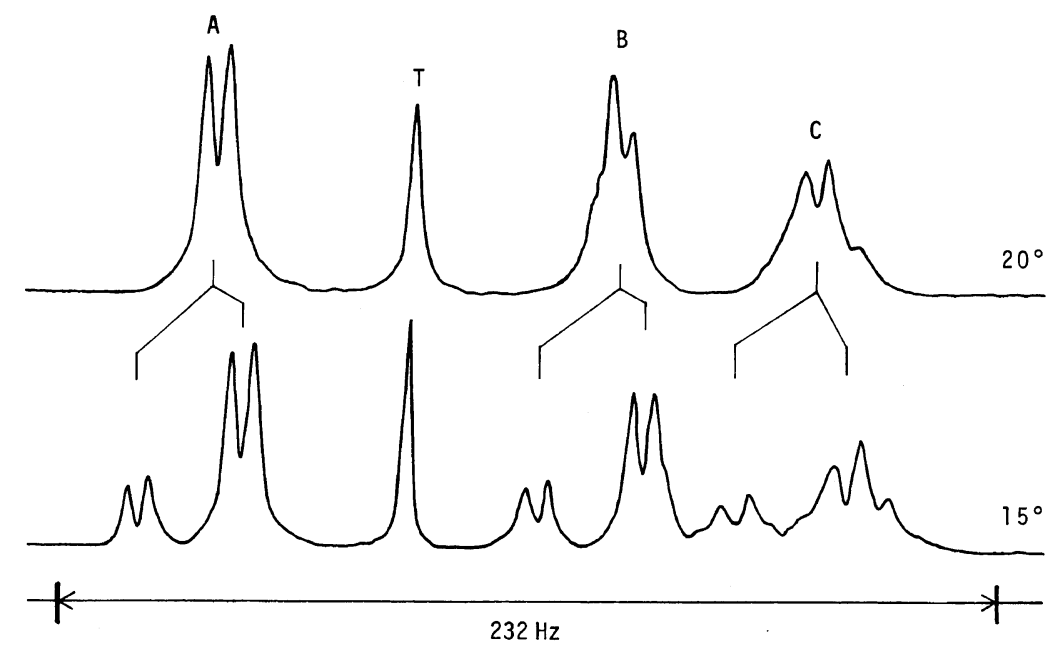

Figure 6. $60 \mathrm{MHz}{ }^{1} \mathrm{H}-\mathrm{NMR}$ spectra of the binary mixture whose initial $\left[\mathrm{Et}_{3} \mathrm{Al}_{2} \mathrm{Cl}_{3}\right] /[\beta$-AL] ratio was adjusted to 0.25 . Peak separation at $15^{\circ} \mathrm{C}$ is due to complexed (lower field) and free $\beta$-AL (higher field). Assignment: (A) $=\mathrm{C} \underline{H}-\mathrm{C}-\mathrm{O}-$; (b) $>\mathrm{CH}-\mathrm{CH}=$; (C) $>\mathrm{C} \underline{\mathrm{H}}-\mathrm{O}-$. Resonance of toleune occurred at $2141.9 \mathrm{~Hz}\left(20^{\circ} \mathrm{C}\right)$ and $2143.0 \mathrm{~Hz}\left(15^{\circ} \mathrm{C}\right)$. 
Copolymerization of $\beta$-Angelica Lactone and Styrene

Table II. ${ }^{1} \mathrm{H}$ NMR data of the ternary system, St- $\beta$-AL- $-\mathrm{Et}_{3} \mathrm{Al}_{2} \mathrm{Cl}_{3}$, at $20^{\circ} \mathrm{C}$

\begin{tabular}{|c|c|c|c|c|c|c|c|c|c|}
\hline \multirow{2}{*}{$\begin{array}{c}\text { Exptl. } \\
\text { No. }\end{array}$} & \multirow{2}{*}{$\frac{\beta-\mathrm{AL} / a l^{\mathrm{a}}}{\mathrm{cm}^{3}}$} & \multirow{2}{*}{$\frac{\mathrm{C}_{6} \mathrm{D}_{12}}{\mathrm{~cm}^{3}}$} & \multirow{2}{*}{$\frac{\mathrm{St}}{\mathrm{cm}^{3}}$} & \multirow{2}{*}{$\frac{[\beta-\mathrm{AL} / a]_{0}}{[\mathrm{St}]_{0}}$} & \multicolumn{5}{|c|}{$\Delta_{\mathrm{obsd}}=\delta_{\mathrm{obsd}}-\delta_{\mathrm{free}}(\mathrm{Hz})^{\mathrm{b}}$} \\
\hline & & & & & $\mathrm{CH}_{3}-$ & $>\mathrm{CHO}-$ & $-\mathrm{CH}=$ & $=\mathrm{CH}-\mathrm{CO}$ & $\mathrm{Al}-\mathrm{C}-\mathrm{CH}_{3}$ \\
\hline 1 & 0.18 & 0.72 & none & 0 & 0 & 0 & 0 & 0 & 0 \\
\hline 2 & ", & 0.61 & 0.11 & $1.15^{\mathrm{c}}$ & -5.2 & -8.4 & -4.3 & -8.7 & 3.2 \\
\hline 3 & " & 0.49 & 0.23 & 2.40 & -11.1 & -18.1 & -9.0 & -19.8 & 7.0 \\
\hline 4 & $\prime \prime$ & 0.29 & 0.43 & 4.48 & -22.9 & -37.0 & -17.5 & -40.8 & 17.4 \\
\hline 5 & " & 0.17 & 0.55 & 5.74 & -26.9 & -42.9 & -20.8 & -46.8 & 21.2 \\
\hline 6 & ", & 0.02 & 0.70 & 7.30 & -35.2 & -55.4 & -27.6 & $\mathrm{~d}$ & 25.9 \\
\hline \multicolumn{5}{|c|}{ Relative shift ${ }^{\mathrm{e}}$} & 0.62 & 1.00 & 0.49 & 1.08 & 0.44 \\
\hline
\end{tabular}

a A mixture of $\beta$-AL $\left(0.08 \mathrm{~cm}^{3}\right)$ and $\mathrm{Et}_{3} \mathrm{Al}_{2} \mathrm{Cl}_{3}\left(0.1 \mathrm{~cm}^{3}\right)$ which is supposed to contain at least $8.3 \times 10^{-4} \mathrm{~mol}$ of the binary complex.

b $\delta_{\text {free }}$ means each chemical shift in the sample No. 1 .

c This is not sufficiently large to use for Hanna-Ashbough's plot.

d This signal overlapped with that of styrene.

e Relative shift is defined in text. These values are averaged from all samples.

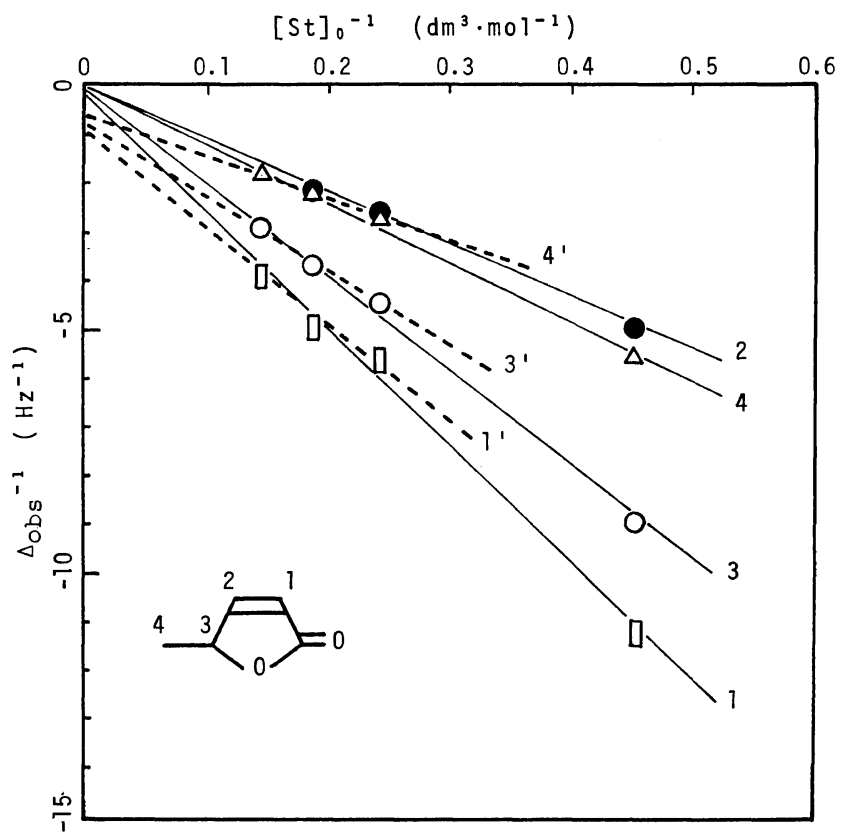

Figure 7. Hanna-Ashbough's plot for the $\mathrm{St}-\beta-\mathrm{AL} / \mathrm{Et}_{3} \mathrm{Al}_{2} \mathrm{Cl}_{3}$ system. Broken lines $1^{\prime}, 3^{\prime}$ and $4^{\prime}$ yielded the stability constant $K$ for the ternary complex, $0.044,0.048$, and $0.050 \mathrm{dm}^{3} \mathrm{~mol}^{-1}$, as well as $\Delta_{\text {comp }}$, $-110,-133$, and $-200 \mathrm{~Hz}$, respectively. See text for explanation of the solid lines.

As the St content increased, the resonances due to $\beta$-AL protons remarkably shifted to a higher field and also those due to Al-ethyl group shifted in the opposite direction. On the other hand, those of St went virtually unchanged. In regard to the $\beta$-AL protons, the relative shifts defined as the ratios of chemical shift difference to that of an alkoxy methyne proton namely $\Delta_{\text {obsd }} / \Delta_{\text {obsd }}$ (for $>$ CHO-) coincided within the experimental error of all the samples. It thus seems that these protons must be 
placed over the magnetic anisotropy of St in a specific arrangement during the formation of a ternary complex such as "St $\cdots \beta$-AL/al."

To estimate the stability constant $(K)$ for the ternary complex formation, the Hanna-Ashbough plot depicted in Figure 7 was used. Each leastsquares line (solid line), however, intercepted so close to zero that the $K$ value could not be determined. In consideration of better linearity at higher concentrations of $\mathrm{St}$, broken lines in this range were employed for this purpose and the $K$ value could be evaluated at most as $0.05 \mathrm{dm}^{3} \mathrm{~mol}^{-1}$. This value is rather small. Furthermore it should be kept in mind that the ternary complex formation would be achieved to a much lesser degree in aromatic solvents such as toluene instead of cyclohexane because of the competitive complexation of the "Solvent $\cdots \beta$-AL/al." This difficulty in forming the ternary complex must be due to the steric interference of the methyl groups of $\beta$-AL during the course of interaction between the binary complex and the incoming St molecule. The higher copolymerization temperature may also be responsible for the decrease in the formation of the ternary complex.

Consequently, organoaluminum chlorides can enhance the double bond reactivity of $\beta$-AL through the nearly complete binary complexation, but these binary complexes lead ineffectively to ternary complexes with $\mathrm{St}$ and give imperfect alternating regularity in the resulting copolymers.

The most noteworthy achievement of the present work is that it provides a convenient route to copolymers containing moderate amounts of lactone units on the backbone chains by copolymerizations of $\beta$-AL which has long been neglected for this purpose. It also points out the significance of the steric requirement in the Lewis acid-complexed alternating copolymerization. Applications of these copolymers in membrane formation will be reported in a future publication.

Acknowledgement. The authors wish to thank Mr. H. Hata of Natoko Paints Co. Ltd., for kindly recording the gel-permeation chromatographs.

\section{REFERENCES}

1. T. Shimidzu, M. Yoshikawa, M. Hasegawa, and H. Chiba, Kobunshi Ronbunshu, 34, 753 (1977).

2. T. Shimidzu, M. Yoshikawa, and K. Kawakatsu, Polym. J., 12, 363 (1980).

3. S. Kobayashi and H. Sumitomo, Polym. Bull., 5, 373 (1981).

4. Y. Iwakura, T. Tamikado, Y. Fujimoto, S. Ikegami, and M. Maruyama, Kobunshi Kagaku, 15, 469 (1958).

5. T. Hirabayashi and K. Yokota, Polym. J., 13, 51 (1981).

6. T. Hirabayashi and K. Yokota, Polym. J., 13, 57 (1981).

7. M. Komiyama and H. Hirai, J. Polym. Sci., Polym. Chem. Ed., 14, 1993 (1976).

8. (a) M. Hirooka, H. Yabuuchi, J. Iseki, and Y. Nakai, J. Polym. Sci., A-1, 6, 1381 (1968); (b) S. Pasynkiewicz, T. Diem, and A. Korol, Makromol. Chem., 137, 61 (1970); (c) M. Hirooka, H. Yabuuchi, S. Kawasumi, and N. Nakaguchi, J. Polym. Sci., Polym. Chem. Ed., 11, 1281 (1973); (d) T. Hirabayashi, and K. Yokota, J. Polym. Sci., Polym. Chem. Ed., 14, 45 (1976); (e) H. Hirai, J. Polym. Sci., Macromol. Rev., 11, 47 (1976).

9. H. K. Hall, Jr. and A. K. Schneider, J. Am. Chem. Soc., 80, 6409 (1958).

10. F. Furukawa, E. Kobayashi, and J. Yamauchi, Polym. J., 2, 407 (1971).

11. T. Hirabayashi, Y. Nishikawa, and K. Yokota, J. Polym. Sci., Polym. Chem. Ed., 17, 3823 (1979).

12. T. Kokubo, S. Iwatsuki, and Y. Yamashita, Macromolecules, 1, 482 (1971).

13. B. K. Patnaik and N. G. Gaylord, J. Macromol. Sci., Chem., A5, 1239 (1971).

14. N. G. Gaylord and B. K. Patnaik, J. Polym. Sci., B, 10, 653 (1972). 